\title{
DULCE PATRIA, \\ UN POEMARIO SOBRE LA DICTADURA CHILENA
}

http://dx.doi.org/10.11606/issn.2237-1184.v0i23p184-201

Horacio Gutiérrez'

Universidade de São Paulo

\section{RESUMO}

As ditaduras do Cone Sul originaram numerosos textos literários que narram a violência ocorrida, querendo servir também de testemunhos. No presente texto apresentamos o poemário Dulce patria, de nossa autoria, publicado em 2012, e que, recriando vozes de diversos grupos sociais, relata a história da ditadura chilena. A violência atravessou o mundo político, o econômico, as relações de trabalho e a cultura, mas manifestou-se também em outros campos, como nos vínculos familiares e o exílio. Interessa no presente texto comentar principalmente as estratégias narrativas utilizadas na confecção do poemário.

\section{RESUMEN}

Las dictaduras del Cono Sur originaron numerosos textos literarios que narran la violencia ocurrida, queriendo también servir de testimonios. En el presente texto presentamos el poemario Dulce patria, de nuestra autoría, publicado en 2012, y que, recreando voces de diversos grupos sociales, relata la historia de la dictadura chilena. La violencia atravesó el mundo político, el económico, las relaciones de trabajo y la cultura, habiéndose manifestado también en otros campos, como los vínculos familiares y el exilio. Interesa en el presente texto comentar principalmente las estrategias narrativas utilizadas en la confección del poemario.

\section{ABSTRACT}

The dictatorships of the Southern Cone originated numerous literary texts that narrate the violence that occurred, and also purport to serve as a testimony thereof. In the present text we present the poem collection Dulce patria (Sweet Fatherland) of our authorship, and published in 2012, which recreates voices from various social groups, and thereby tells a history of the Chilean dictatorship. Violence crossed over the political and economic world, as well as labor relations and culture, and also manifested itself in other fields, such as family ties and exile. The present text aims to comment mainly on the narrative strategies used in creating the poems.

\footnotetext{
${ }^{1}$ Historiador e docente do Departamento de História da Universidade de São Paulo.
}

\section{PALAVRAS-CHAVE:}

Chile.

Poesía.

Ditadura.

Trauma.

golpe de estado.

literatura latino-americana.

\section{PALAVRAS CLAVE:}

Chile.

Poesía.

Dictadura.

Trauma.

golpe de estado.

literatura latinoamericana.

\section{KEYWORDS:}

Chile.

Poetry.

Dictatorship.

Trauma.

coup d'etat.

Latin American literatura. 
ulce patria es un libro centrado en un único tema, la dictadura chilena (1973-1990), compuesto de poemas que dialogan entre sí. Fueron ordenados prestando atención a la secuencia de sucesos ocurridos a lo largo de los 16 años de régimen militar.

El poemario no es, o no se propone ser, el relato de una experiencia subjetiva y personal del autor, ni la voz de un hablante que resume una experiencia colectiva. Tampoco es un libro de denuncia, porque fue escrito casi 20 años después de terminada la dictadura, y la denuncia de sus atrocidades ya ha sido hecha por otros. Lo que el poemario hace es proceder a la reconstitución de un proceso histórico, intentando contribuir, desde la literatura, en particular desde la poesía, a la construcción de una memoria colectiva. Formaría parte del género conocido como poesía política. La escritura comenzó en 2008 y su publicación ocurrió en Chile, en 2012. ${ }^{2} \mathrm{La}$ intención del presente texto es principalmente comentar las estrategias narrativas utilizadas en la confección del poemario.

\section{La memoria}

El recuerdo de la dictadura en Chile y la construcción de su memoria han labrado su propia historia, pasando por varios momentos. El poemario transitaría por un tema que en la década de los 90, con el fin de los militares en el poder, estaba cansando a muchos. Si la generación de los perseguidos, presos, exiliados, torturados, no paraba de hablar en la época de la dictadura -y después - de las violaciones a los derechos humanos, la siguiente, hijos de la primera, había crecido oyendo hablar del golpe, la Junta, la censura, los abusos, y parecía estar harta del tema. Tocar el asunto recibía una respuesta casi previsible: ¿de nuevo lo mismo? Tanto que la nueva narrativa chilena de los 90 es considerada despolitizada, porque optó por propuestas y tramas más intimistas, con poco compromiso político, o simplemente ajena a él: parecía una generación cansada de "problematizar". Esto me atormentaba.

\footnotetext{
${ }^{2}$ GUTIÉRREZ, Horacio. Dulce patria. Santiago: Ril Editores, 2012, p. 194
} 
Afortunadamente la tercera generación, la de los nietos, grosso modo, cambió. Renace el deseo de saber lo que había pasado, aclarar lo que se murmuraba y que sus padres no le habían contado. ¿Por qué no me contaron? era ahora la pregunta. Empieza nuevamente una demanda por informaciones de la dictadura y avidez por documentales, ensayos, exposiciones, libros de literatura. Ayudó a este "redescubrimiento" el hecho de que a fines de la década de los 90, luego de la prisión de Pinochet en Londres, no siendo más él dictador ni jefe de las fuerzas armadas, sino un senador vitalicio, empezaron las víctimas y entidades de derechos humanos a presentar a la justicia una sucesión interminable de denuncias contra los atropellos ocurridos en el período militar. Así, el tema de la dictadura volvía a la orden del día en la prensa, y así continuaría, hasta hoy. En la actualidad se debe a que casi no hay semana en que no se resuelva en los tribunales un caso más de los juicios que antes se habían presentado, reactualizándose el asunto dictadura en una secuencia avasalladora, permitiendo a los que no vivieron los hechos conocer lo que sucedió, y a los que lo vivieron revivirlo, pero ahora colmado de detalles e ilaciones, y con el nombre de los victimarios al desnudo.

Cuando empecé escribir el poemario, lo que recordaba sobre la dictadura eran fragmentos, a veces detalles minuciosos de la vida diaria, o análisis de conjunto que había escuchado en la época. Los siete primeros años del régimen militar, hasta 1980, los había vivido en Chile, y los siguientes en el exterior, en Brasil, adonde había llegado a continuar estudios, pasando en São Paulo a colaborar con Comités de Solidaridad, integrados por miles de exiliados y refugiados del Cono Sur. Esto me dio una visión amplia de la dictadura, o al menos así lo creía. Posteriormente, informándome mejor sobre lo ocurrido, cada día brotaban acontecimientos sobre los nunca había oído hablar, o conexiones entre hechos que no imaginaba que pudieran haber existido. iSe debería esto a la censura de la época, que todo lo truncaba, o a las medidas de seguridad que se seguían en la resistencia, que exigían conocer el mínimo posible sobre el entorno? La respuesta era que sí, era esa una razón, pero entonces descubrí otra, sorprendente y perturbadora, las características de la memoria. Esta es capaz de filtrar, seleccionar eventos, enaltecer experiencias, diluir incidentes, relacionar situaciones, establecer causalidades, en fin, construir un pasado y hasta recrearlo. Había una distancia entre la memoria y el registro de los hechos, y sucede que lo que se recuerda puede ser tan importante como lo que no se retiene. No es lo mismo escribir un "Diario de vida" que redactar "Memorias" a posteriori. Infelizmente, salvo episodios aislados, no compuse un diario durante la 
dictadura que, por lo demás, las medidas de seguridad lo habrían desaconsejado.

Este conocimiento fragmentario es propio de las generaciones postdictadura, que no vivieron los hechos y se enteraron de ellos oyéndolos o estudiándolos. Pero con grados diferentes, también ocurrió con los que vivieron bajo el régimen militar, por las razones mencionadas. Quería que esta percepción parcial, así como los recuerdos selectivos y desbordados, estuvieran presentes por lo menos en algunos poemas.

Los muertos brotaban en el Mapocho

como peces gigantes y amarillos

y corrían río abajo, en desbandada

inundando los costados

bajo la mirada atónita del cielo

y de los niños

que no podían creer

parecía un cuento macabro:

pedazos de ropas afloraban en el agua

y los perros entraban a rescatarlos

con aullidos que partían el alma

y calentaban la sangre

haciendo coro con el grito de una madre

en el rincón de un puente

que lloraba desconsolada

Dios mío, no puede ser

y gente se aglomeraba estupefacta

dónde están los bomberos

y las ambulancias que no llegan

parecía fin de mundo

o el inicio de otro

pero no se oía casi nada

porque el ruido de las olas subía por el cuerpo

y paralizaba los brazos

y las piernas

y anudaba la garganta

cegando los sentidos

dónde está tu padre

dónde está tu padre

anda a buscar a tu padre

\section{Estrategias narrativas}

Para la escritura del poemario se presentaron varias estrategias posibles de seguir, y el reto era cuál escoger. El tema me pareció que exigía determinado tipo de escritura, o sea, algunas formas serían más aptas que 
otras. La idea era que la elección fuera congruente con el tema, eficaz para el fin deseado, pero también que estuviera al alcance de mis posibilidades literarias y que me dejara conforme. No fue fácil encontrar inmediatamente el rumbo, pues disyuntivas inesperadas se interponían conforme avanzaba, obligándome a decidir entre alternativas.

Apareció el primer dilema: en un poemario de este tipo, o sea, con tono social ies posible distanciarse del "yoísmo", que parece ser el recurso por excelencia presente en toda poesía? ¿No sería absurdo seguir esta práctica en un poemario que pretendía recoger luchas colectivas? No lograba dar con una respuesta concluyente. Pablo Neruda lo incorporó, y alcanzó resultados admirables: recuérdese, por ejemplo, "Explico algunas cosas" o "Alturas de Macchu Picchu". No era, sin embargo, el camino que aspiraba a seguir. Mi apuesta era descubrir otro registro poético viable para el tema y que se mostrara eficaz. No deseaba ser el personaje de mis poemas, por legítima que fuera esta opción. Pero otra interrogante se intercalaba: ¿es posible en poesía separar lo biográfico? ¿Puede la poesía conmover sin relatar un testimonio personal?

A propósito de esto, otro asunto apareció frente a mí. Había temas delicados o sensibles para narrar, como las torturas, las muertes, los desaparecidos, si bien serían contadas dos o tres décadas después de ocurridas. Las imágenes de vidas truncadas pueden parecer hoy, para lectores que no conocieron esas vidas ni vivieron esos hechos, intrascendentes. Como las muertes en muchas películas de acción. Quería humanizarlas. ¿Cómo hacerlo? Se me ocurrió que cobrarían vida sólo en la medida en que emocionen, o sea, que toquen la sensibilidad del lector, que este sienta esos eventos como propios y esas historias de vida como suyas. Los poemas deben emocionar, sentencié, y me convencí de ello. Pero surgía un escrúpulo cruel y hasta tragicómico: ¿es entonces el melodrama el único género apto a una literatura post-catástrofe?

Otras alternativas se presentaban: ¿Sería posible mostrar la realidad con diversas caras? Esta opción me fue gradualmente seduciendo y finalmente, pensando mejor, me encantó. Para ello convocaría a un coro de voces, transcribiría el habla de grupos sociales, de gente común y también de golpistas. Pero descubrí en la práctica que no era tan fácil: luego el coro se tornó polimorfo, permitía o abría la opción de construir más de una imagen de la dictadura, como de hecho ya se han construido diversas en el ensayo, la literatura o echando mano a otros soportes culturales. El poemario, quiérase o no, moldaría un determinado perfil y el problema que se planteaba era cuál entretejer, desde cuál punto de observación, y estar consciente, hasta donde 
fuera posible, del resultado y sus implicaciones. ¿O sería posible también componer más de una visión dentro del mismo poemario, sin preocuparse que visiones alternativas o hasta contradictorias pudieran cohabitar? ¿Sería entonces como una obra de teatro con personajes que emiten opiniones diferentes dialogando entre sí o, aún más, que formulan discursos opuestos? ¿Los personajes representarían grupos sociales? Otra cuestión era la selección de las voces: ¿cuáles, con cuál densidad? ¿Se repetirían en diversos poemas? ¿Cuántas veces? Era evidente que entre todas ellas habría que seleccionar, sería imposible incorporarlas todas, y esa elección representaría sin duda un filtro que incluiría con más visibilidad determinados sectores y dejaría menos audibles a otros.

En suma, el poemario requería una planificación. De hecho, no resultó de inspiración casual, sentado en la noche mirando la luna, o fruto de lo que iba leyendo o recordando de mi experiencia personal. Sentí que la inspiración actuaba, pero a posteriori, una vez definido el tema y el tono que el poema debería tener. En ese sentido no es autobiográfico. ¿El poemario se estaría proyectando en función de obsesiones o en función de convicciones?

El lenguaje que debía usar en mi coro de voces es otro asunto que me quitaba el sueño. Las razones eran varias y, conforme vencía obstáculos, los dilemas se multiplicaban. Uno: no quería usar chilenismos, o entonces restringirlos al mínimo, de modo que el poemario pudiera ser comprendido sin dificultades por lectores de lengua castellana de otras latitudes, principalmente de aquellos países que también habían pasado por dictaduras. ¿Pero esto no era contradictorio con la opción de privilegiar voces de diferentes grupos sociales? ¿Cómo tornar reconocible el habla del dictador en los poemas y el de muchos ministros y autoridades militares, si eliminaba los chilenismos, en circunstancias que ellos hablaban principalmente con chilenismos y en registro campechano?

Dos: en decisión súbita opté por escribir preferencialmente poemas sucintos con versos cortos, porque noté que me salían con más naturalidad, aunque después de tomada la decisión, y ya con varios poemas escritos, quedé pensando y quise saber si estaba en lo cierto. ¿Era esta modalidad la más adecuada para lo que me proponía? ¿Por qué seguir un estilo epigramático, seco, directo, casi sin metáforas? ¿Eran exigencias impuestas por el contexto histórico que el poemario quería retratar, y que englobaba a sus personajes y sus discursos, o se trataba de preferencias personales un tanto insondables? ¿O sería porque el contexto militar, que corresponde a mis años de formación, me acostumbró a ese estilo, que ahora quería incorporar al poemario? Sea cual fuere la respuesta, es ese estilo el que 
terminó siendo preferentemente adoptado. En lo que al contexto histórico se refiere, este se caracterizaba por una coyuntura donde la censura no dejaba hablar, los discursos debían ser breves, los rayados callejeros cortos, para que pudieran ser realizados en pocos segundos, y luego salir corriendo. No había espacio para explicaciones extensas, para discutir razonadamente, al contrario, lo ideal para mantenerse incólume era no hablar en público, no ser observado, pasar desapercibido. Este comportamiento era el vigente en Chile, pero también lo viví en Brasil, adonde llegué cuando la dictadura local aún no terminaba, conducta que en mi caso tuvo en alguna medida que prolongarse después de concluida, pues la leyes brasileñas que prohibían a los extranjeros de "participar en política" continuaron en vigor.

Tres: Prestaría mucha atención al ritmo y sonoridad de los poemas. Era algo que me atraía, y que permitiría además transformarlos en poemas orales, para ser leídos en voz alta, frente a un público, otra cuestión que me cautivaba. Cabría entonces fijarse en los ritmos distintos de las distintas voces.

\author{
Duérmelos con un somnífero \\ inmovilízalos de brazos y piernas \\ sujétales un pedazo de riel al cuerpo \\ embárcalos en un helicóptero \\ y cuando estés volando, \\ en alta mar, \\ suéltalos. \\ El golpe los sumergirá para siempre \\ en la gloria de Dios.
}

Amor, si un día tú apoyaras a la dictadura, te besaría sin parar hasta sofocarte como a un prisionero.

Mi deseo era ambientar el poemario con el habla y la cultura de las décadas del 70 y 80, sin tener que dar explicaciones. Se me ocurrió que una forma sería reproducir consignas, pedazos de discursos, de músicas o de literatura de la época, recurrir a muletillas, cacofonías, aunque sin parecer panfletario, a semejanza de un Museo del Holocausto, donde el visitante, sin mediar aviso alguno, de repente se encuentra en el centro de un campo de concentración, sintiendo en la piel lo que habría experimentado un recluso. Pero un temor me asaltaba: ino sería aquello un plagio, minúsculo, irrelevante, pero plagio al fin? ¿O sería antes un injerto? En mi poca familiaridad con la literatura, o con la teoría literaria, le comenté esto a un colega, que me tranquilizó. Es un recurso literario legítimo, me informó, y 
muy antiguo y difundido, que en literatura tiene hasta un nombre propio: intertextualidad. En artes plásticas tiene otro: collage. La opción estaba definida.

Si de recuperar el habla de los 70 y 80 se trataba, era necesario incorporar el humor. El humor negro y la humillación de los opositores fue un expediente habitualmente utilizado por los mandos castrenses y civiles, no sólo en sesiones de tortura, sino públicamente, en las radios, los discursos oficiales, en ruedas de prensa. ¿Sería acertado incorporar esta dimensión a los poemas? ¿Cómo hacerlo sin ofender, sin reforzar estereotipos, sino al contrario, desenmascararlos?

En las fosas comunes camine sin tropezarse.

¿Fosas comunes? ¿Qué difamación es esa?

Deben agradecer porque fue una economía muy grande

haber sepultado dos cuerpos en una misma tumba.

Descubrí, sin embargo, que había más de un tipo de humor en contienda. La oposición, cuando pudo reorganizarse y empieza a externalizar sus protestas, también lo incorpora, pero con significados diferentes, en general para aliviar tensiones y principalmente para deslegitimar al gobierno. $\mathrm{Su}$ uso, empero, pareció restringirse a ambientes más privados, entre conocidos.

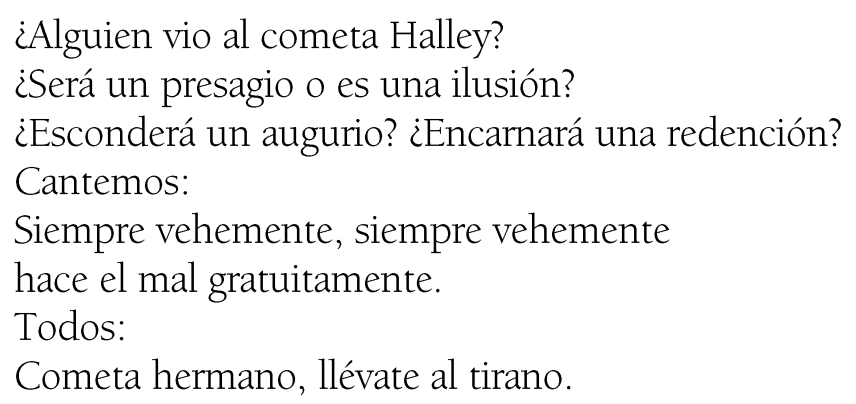

Incorporando la dimensión del humor, Dulce patria podría parecer tributario del lema de los Ig Nobel, descubrí después, con cierta desazón. En este caso, presentaría poemas que "primero hacen a la gente reír, y después pensar". ¿Sería este el resultado? Si lo fuera, imaginé luego, va a ser un obsequio, ojalá ocurra, es eso precisamente lo que me gustaría. Y me di por satisfecho.

Volviendo a la izquierda, era preciso enfrentar una controversia que remeció a la oposición por entero. En el período anterior a la dictadura, o sea, antes de la década del 70, la izquierda chilena (y latinoamericana podemos 
agregar) nunca incorporó seriamente como un valor en sus plataformas políticas la defensa de los derechos humanos, tal como expuestos por ejemplo en la Declaración Universal de las Naciones Unidas de 1948, y menos aún en el sentido todavía más amplio que actualmente tiene. Su interés en el tema comenzó durante la dictadura, en virtud de las violaciones sistemáticas de que eran víctimas sus militantes y simpatizantes. En los partidos no fue una discusión fácil y el debate llevó a cuestionamientos de concepciones políticas arraigadas, como las vías hacia la revolución, la dictadura del proletariado, redundando en divisiones internas, disidencias y formación de nuevas corrientes políticas. Dentro de la izquierda se había descubierto que existía no sólo una derecha autoritaria, sino también una izquierda autoritaria, y habría que fundar otra, una izquierda democrática. Esta crítica emergió en el caso chileno principalmente entre los exiliados residentes en Europa. El asunto era explosivo y se evitaba su discusión al interior del país porque frente a la máquina de exterminio que representaba la dictadura, el llamado era a congregar, no a dividir.

La interrogante que me roía era: ihacer un poemario sobre una dictadura de derecha con críticas también a la izquierda? ¿A quién está dirigido el poemario? ¿No corría el riesgo de quedarse sin lectores ni críticos, principalmente en Chile, donde la filiación partidaria es un trazo prominente de identidad, aún hoy? ¿Debe escribirse una obra pensando en un público? ¿Tiene sentido un poemario de poesía política no tener público lector?

\footnotetext{
Un revolucionario no debe pasearse en la playa con sunga rosada.

¿Después de cuántas revoluciones se alcanza la felicidad?
}

Dos opciones estaban claras: me interesaba un público lector y, segundo, las críticas o reformulaciones que la izquierda levanta en ese entonces no deberían ser omitidas. ¿Pero deberían ser expuestas en qué dosis, con cuál modulación?

De todos modos, la idea sería aprovechar la polémica para insertarla en la discusión más amplia de la sociedad que queremos, qué es una dictadura, qué es una democracia, qué es libertad, qué es justicia social, con las implicaciones sociales, políticas y éticas que ellas pudieran envolver. Escribir sobre la dictadura tendría así un sentido para el presente, y llenaría de nuevos significados slogans memorables y vitales como el que todos alguna vez pronunciamos: ni perdón, ni olvido. 


\section{Desafíos}

Las estrategias narrativas escogidas me obligaron a enfrentar desafíos variados, algunos de investigación histórica y otros literarios, desafíos con los que me fui topando mientras escribía. Comento tres.

Para la redacción del poemario, y queriendo lograr verosimilitud, procedí a una vasta investigación de fuentes. No me fiaría de la memoria únicamente y resolví ir a la zaga de testimonios, informes de derechos humanos, recortes de prensa, discursos, propaganda, panfletos, grafitis, películas, músicas de época, así como revistas publicadas en ese entonces. La llegada de la red facilitó las cosas. Me empapé de bibliografía histórica, y también de literatura, principalmente de aquella conocida como "novelas del dictador". Menos suerte tuve con la poesía política, que en el caso chileno circuló primordialmente en ediciones mimeografiadas, es decir, de difícil acceso, hasta hoy. Desafortunadamente en esa búsqueda no encontré algo que deseaba: "poemarios del dictador", a semejanza de las novelas. ¿No di con ellos, o ellos no existían?

El impase más brutal, sin embargo, lo viví al iniciar el poemario, y me dejó aturdido: estaba muy olvidado del castellano. Vivía en Brasil hace casi tres décadas y en ese tiempo tuve que aprender a expresarme en portugués, habiéndome alejado del castellano conscientemente, para no mezclarlo. El aprendizaje, dada mi poca facilidad para lenguas, había sido traumático. Quise entonces escribir el poemario en portugués. Tenté, tenté y no salió nada. Este resultado me condujo a otro hallazgo: mi lengua literaria era el castellano, que era mi idioma materno y mi lengua cotidiana hasta concluir la universidad en 1980, en Chile, antes de viajar a Brasil. En ella parecía sentirme desenvuelto, sabía con más precisión el significado de las palabras, o mejor, sus alcances diversos, podía diferenciar el lenguaje coloquial, el ampuloso, el periodístico, el arcaico, el irónico, sintiéndome capaz de transformar el texto de un estilo a otro, y captar sus ritmos y sonoridades. Me empeñé entonces en otra tarea, ardua: reaprender el castellano.

Además de la investigación histórica inicié, así, una extensa pesquisa de lenguaje que se ensanchó, enseguida, con la finalidad no sólo de recuperar el castellano, sino atender a la estrategia narrativa escogida: necesitaba saber cómo los grupos sociales hablaban, cómo se expresaban. ¿Qué rezaba una madre al entrar a una iglesia y pedir por su hijo desaparecido? ¿Qué gritaban los estudiantes cuando desfilaban por las calles? ¿Había diferencias en las palabras usadas por los distintos partidos en sus textos clandestinos? ¿Qué lenguaje empleaban los militares en sus alocuciones de radio y TV? ¿Cómo 
un niño se refería a los sucesos que estaba viendo? Era imprescindible consultar fuentes de época. Elaboré también largas listas de palabras y giros lingüísticos que deberían constar en los poemas.

Otro desafío fue incorporar la voz de los perseguidos. Al decidir ordenar los poemas en secuencia cronológica, acompañando temporalmente los eventos ocurridos en dictadura icómo incorporar en la parte inicial del poemario a la resistencia, si esta no se oía, porque estaba clandestina y censurada? La solución fue escucharla de forma indirecta, a través del discurso oficial que era el único autorizado en los medios de comunicación. Surgía el reto de desenmascarar al régimen con sus propias palabras, y no con las de sus opositores, que poco figurarían en el primer tercio del poemario.

\section{El liberalismo}

Si bien el golpe chileno fue ejecutado para detener el proyecto socialista de Salvador Allende, no había inicialmente claridad sobre la posibilidad de implantarse un modelo liberal de economía. Los militares habían sido azuzados permanentemente a levantarse para frenar las estatizaciones, la reforma agraria y las conquistas laborales, y para eso contaron con el respaldo de poderosos grupos económicos chilenos y extranjeros. La represión, para consolidar el golpe, tuvo que ser brutal, y así prosiguió, con ciclos, hasta el final del régimen. Fue escalofriante constatar que la dictadura consiguió apoyo a pesar de los desmanes y atropellos que todos conocían, principalmente en lo que a secuestros, torturas y asesinatos se refiere, aunque tal vez no fuesen visibles todavía en la extensión y perversidad que después se verificaron. Pero por otro lado, las exoneraciones, prisiones y exilios eran públicas, es decir, inmediatamente conocidas y, villanía suprema, fueron celebradas por la prensa y agentes del gobierno, contando incluso con el aplauso cómplice de varios sectores de la población. Estos puntos de vista deberían ser relatados, pensaba yo, porque fueron tremendos, y en mi cabeza, ignominiosos. ¿Alguien podría negar que se había instalado en el país un régimen autoritario, después que el golpe se iniciara con el bombardeo del palacio presidencial, y afirmar que era la libertad y la democracia lo que se había ganado, y al mismo tiempo constatar que había estado de sitio, coerción generalizada y un Congreso clausurado?

Libres, libres al fin

como el sol cuando amanece

libres, con los ojos humedecidos de emoción

somos libres, libres para cantar y gritar al viento 
libres como el ave que escapó de su prisión

Dios mío libres, libres mi general, liberador del comunismo

libres y radiantes, y con el horizonte iluminado

encantadas aportaremos con dinero

agradecidas donamos nuestras joyas

libres con nuestros hijos

y libres para la reconstrucción nacional.

¿Ingenuidad? ¿Cinismo? ¿Fanatismo? La verdad es que la palabra libertad, así como los conceptos de dictadura y democracia, comportan diversos sentidos e intenciones, algunos incluso contrapuestos. Pero mi preocupación era otra: ¿es posible capturar estos significados? ¿Sería factible traspasarlos a poemas?

Por otro lado, el régimen chileno, o su núcleo neoliberal, tuvo ambiciones económicas inauditas que constituyeron, quizás, lo central de todo. El problema para ellos era armonizarlas con una democracia liberal. Inicialmente, cual conquistadores del siglo XVI, los militares emplearon métodos de tierra arrasada, aunando esfuerzos para eliminar todo vestigio de reformas sociales, de socialismo y de revolución. En el poemario quise evocar esta furia demoledora.

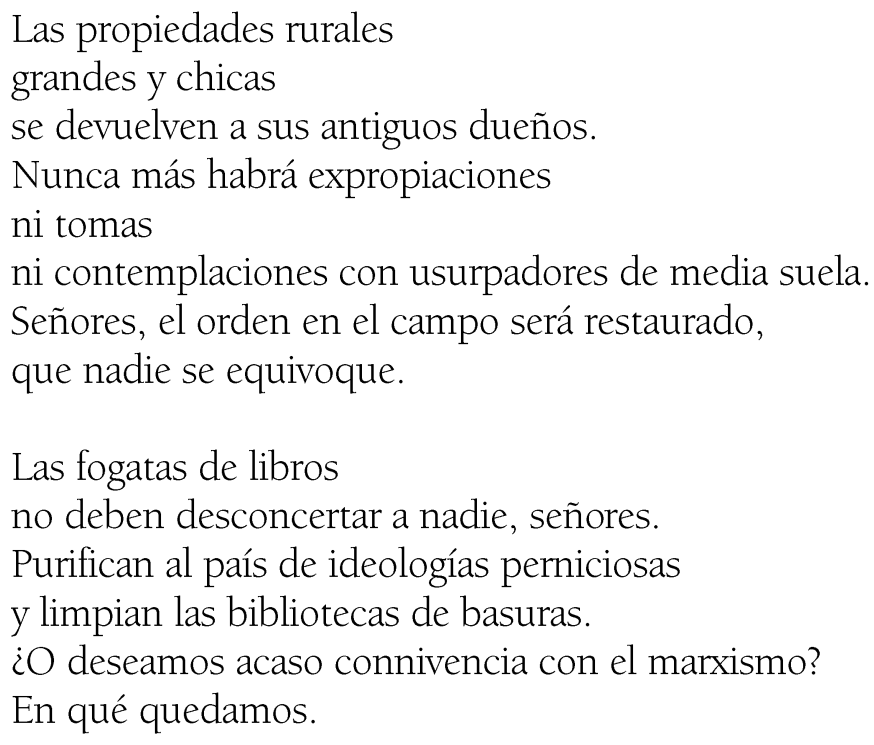

Luego, en un segundo momento, con mucho orgullo, lo declaran expresamente, los miembros de la Junta Militar deciden encarnarse en próceres de la independencia, anunciando la refundación de Chile. Presionados por los grupos de poder que promovieron el golpe, ingresan al gobierno los llamados Chicago Boys, que implementan un programa económico liberal implacable, que habían diseñado con anterioridad. 
Sabiendo que la resistencia sería enorme, dado su costo social altísimo, fuerzan el cambio, equipados de plenos poderes.

El país se está abriendo hacia el mundo

y viceversa

gracias a un programa fiscal y monetario inflexible

que todos esperábamos

implementado con hombría y decisión firme

como se debe

con el total respaldo del Banco Central

tan necesario

y que respeta el principio de la libertad

un hecho inédito

además de crear empleos directos e indirectos

que es lo que deseamos todos

sin recurrir al déficit público

un triunfo

e ideado incluso con mecanismos anticíclicos

gracias a Dios

y antiterroristas

oh! gracias, gracias, es un alivio.

La acción de la mano invisible, señores, es el mejor invento de la economía liberal y también de mi gobierno.

¿Este liberalismo económico era compatible con la democracia liberal? Las medidas económicas eran tan concentradoras de riqueza y cercenadoras de derechos sociales y laborales, aplastando salarios y excluyendo mayorías, que era imposible llevarlas a cabo con sindicatos, partidos y parlamentarios. Se postergó indefinidamente la vuelta a la democracia liberal y en su lugar se fue desarrollando la idea de una "democracia protegida". En este contexto la represión, que inicialmente sería fundamental para desarticular la resistencia al golpe, se mostraría acorde y intrínsecamente necesaria al nuevo modelo económico buscado, dependiendo de ella el éxito de su implantación y continuidad. ¿La libertad propalada consistía entonces en dejar funcionar libremente al mercado, sin controles, nada más?

Basta dirigir durante el día una mirada a la cordillera y en la noche otra al firmamento para concebir desde luego la grandeza de Dios fuente de autoridad de nuestro gobierno y frente a la cual la democracia, señores, no vale nada

nada

nada. 
La libertad ha sido nuestro blanco

- la estamos aprovechando mucho

salvamos a la patria del comunismo soviético

- fue una hazaña

exterminamos a los subversivos

- muy bien hecho

tomamos presos a los activistas

- se lo merecían

e impusimos una democracia protegida e indestructible:

esto es lo que no me perdonan.

\section{Exilio y resistencia}

Yo no vivo en mi país

ni en un país extranjero,

vivo en el exilio.

El destierro cuenta con viejos precedentes en Chile, pero fue durante la dictadura la primera vez que ocurrió en masa, de norte a sur, con repercusiones personales, y en las familias, devastadoras. Pasó por fases. En los primeros años incluyó a autoridades y líderes del antiguo gobierno que debían dejar el país por expulsión sumaria, asilo en embajadas, o decisión propia. Luego vendrían avalanchas de desterrados económicos, "los que sobraron", o sea, los excluidos por el modelo económico. Fueron cientos de miles a lo largo del régimen y casi no hubo país donde algún chileno o familias enteras no arribaran.

El exilio, señores, es un estado de espíritu

risueño y dorado

y por lo que estoy viendo

hay muchos que están deseosos de alcanzarlo.

Los sarcasmos del gobierno calaron hondo en sus seguidores y en no pocos militantes de izquierda que también abrazarían esas palabras como suyas. En el exterior, refugiados e inmigrantes se depararían con ambientes nunca imaginados: idiomas extraños, sociabilidades nuevas, comidas deliciosas, o intragables, y la sensación de hallarse desamparados frente al mundo, sin compañeros, amigos, o familiares. Muchos venían de centros de detención, otros con cónyuge e hijos, y cuando sentían condiciones ásperas de arraigo, emprendían nuevos rumbos. La solidaridad fue una cuestión de piel: se dirigía a los recién llegados y a los compatriotas que luchaban en el 
terruño, buscándose apoyos, condenando arrestos, replicándose protestas, recaudando dinero. Superada la dictadura, el tiempo transcurrido hizo que muchos, por cuestiones de trabajo, o con hijos nacidos y criados en el exterior, no pudieran regresar, rehusándose a tronchar nuevamente lazos familiares. Entre los que volvieron, muchos tendrían un segundo exilio: el país al que llegaban no era más el que habían dejado, había cambiado, y la sensación de extrañamiento los abrumaría para siempre. ¿Diáspora, exilio, migración, cuál sería el término más apropiado?

Dentro de Chile, los principales agentes de la resistencia a la dictadura fueron los antiguos partidos (resquebrajados y actuando en la clandestinidad), la Iglesia Católica, los estudiantes, las pobladoras. Los golpes propinados a obreros y campesinos, fuerza motriz de la Unidad Popular, hicieron que perdieran empuje y protagonismo, quedando muy neutralizados en su poder de contestación. La resistencia transitó también por ciclos. Los primeros años fueron de reflujo, pero ya a fines de los 70 la resistencia comienza a aparecer, tornándose cada vez más pública en la década siguiente, principalmente a partir de 1983, cuando las Jornadas Nacionales de Protesta se toman las avenidas. Años antes, y como respuesta a los afanes del gobierno militar de institucionalizarse disponiendo una nueva Constitución en 1980, habían surgido nuevos grupos guerrilleros de resistencia armada.

En dictadura todas las formas de lucha son legítimas.

Asiste al pueblo el derecho a rebelión.

Es lícito matar a un tirano.

Las mujeres desempeñaron un papel singular en la resistencia civil. Pobladoras residentes en barrios periféricos, esposas e hijas de presos políticos, madres de detenidos desaparecidos, parientes de estudiantes relegados, con militancia política o sin ella, asumen papeles protagónicos, encabezando Agrupaciones de Derechos Humanos y dando la cara frente a la policía, las autoridades y la prensa.

Hasta cuándo cercan nuestras calles.

Hasta cuándo invaden nuestras casas.

Hasta cuándo encañonan nuestras familias.

Hasta cuándo detienen a nuestros hombres.

Hasta cuándo matan a nuestros líderes.

Hasta cuándo nos insultan y nos humillan.

iHasta cuándo! iHasta cuándo!

El dictador no tardaba en responder. 


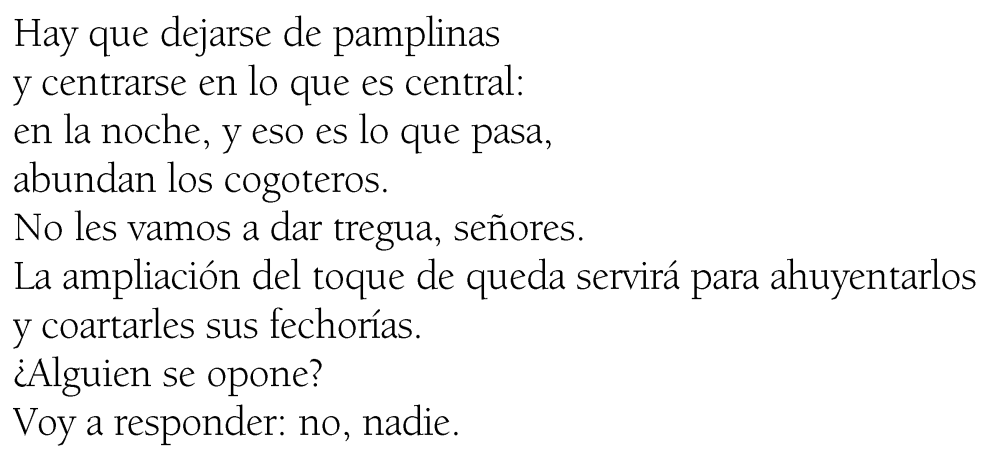

La resistencia no fue sólo política y armada, sino también cultural. Los primeros años asisten a lo que se denominó apagón cultural, simbolizado por las fogatas públicas de libros. A fines de los 70 se empezó a perder el miedo, y entre los jóvenes ya surgen las fiestas de "toque a toque" (se extendían por la noche, atravesando el inicio y el fin del toque de queda). La actuación de la Agrupación Cultural Universitaria (ACU), fundada en Santiago, haría historia con sus festivales de música, donde brillaría el Canto Nuevo, y festivales de teatro, semillero de futuros dramaturgos. En los años 80 se consagra la banda de rock Los Prisioneros, con su irreverencia y canciones contestadoras. Nuevas revistas, como La Bicicleta, cubren inquietudes juveniles con lenguajes renovados y postura opositora. En fin, las antiguas peñas y casas de espectáculos, clausuradas, darían lugar a nuevos centros y manifestaciones, sorteando la censura e instituyendo una resistencia cultural que estaría presente en todos los actos políticos, y también en misas y romerías.

Sobre fotografías de archivo

sobre carpetas y libros

en postales solidarias

escribimos tu nombre.

Sobre tapices de lana

pisando la arena

en pulseras y collares

grabamos tu nombre.

Sobre murallas de cal

en azulejos de baños públicos

en panfletos callejeros

estampamos tu nombre.

Sobre hombros desconocidos

en peñas y recitales

alegrando fiestas hogareñas

cantamos tu nombre. 
Sobre pedestales y escenarios

en mítines políticos

por sobre las multitudes

gritamos tu nombre.

Tú vives.

\section{Reflexiones finales}

Dulce patria no es un testimonio sobre la dictadura, una crónica en verso, una poesía de denuncia, de catarsis, de autoconocimiento, de fruición artística, o mejor, también lo es, aunque su principal sentido lo veo situado en otro terreno, el político. Reivindico Dulce patria como un poemario de poesía política.

Se afirma que interesa a la poesía, y a la literatura en general, desvelar la condición o naturaleza humana, y nosotros agregaríamos que también la naturaleza de las sociedades, de lo social, entes que parecen tener, afirman algunos sociólogos con buenos argumentos, dinámica propia, o por lo menos formas de funcionamiento distintas o autónomas, exteriores a la naturaleza humana. ¿Sería posible hacer claramente esta distinción? Si ella existe, y me inclino a creer que pueda hacerse, es legítimo que ese territorio sea ocupado también por la poesía, pudiendo la poesía política entenderse como parte de la literatura con vertiente social.

Esta poesía, de factura bastante antigua, es un género a veces despreciado por su asociación con la invectiva, el panfleto o el carácter temporal de su contenido. El tono de esta poesía ha variado desde la utilización de frases serias, doctrinarias y edificantes, pasando por el empleo del humor y la sátira, hasta la poesía solemne, grandilocuente y redentora.

Haciendo lecturas, percibí que mucho del desdén por la poesía política se debía a las fronteras difusas que tendría con el proselitismo, y aparentemente esta inflexión no sólo sería desagradable, sino inaceptable en literatura. Pero acoger esta tesis ino significaría eliminar de plano la literatura con compromiso social? ¿No fue esta precisamente la literatura más difundida en tiempos de la dictadura, cuando se necesitaba una poesía de combate, no para derrocar al régimen, sino para denunciar sus atropellos, exaltar a los caídos, restituir la dignidad a los perseguidos, fortalecer la moral de los combatientes y robustecer la lucha? De hecho, era esta la poesía que se recitaba en los actos culturales, en las protestas, en los cementerios y se reproducía en grafitis y pancartas. Quiero creer que independientemente de los gustos personales (en mis preferencias tampoco está la poesía panfletaria) 
es un género con derecho a existir y a ser valorizado, a ser considerado tan legítimo como los demás estilos.

"Poesía política", por lo demás, parece ser una denominación redundante: ¿cuál poesía o producto literario no lo es? ¿Cuál artefacto artístico o cultural no incorpora esta dimensión? Ya ha sido llamada también, salvando los matices, poesía social, de lucha, de combate, rebelde, comprometida, de la resistencia, insurgente, guerrillera, modalidades que constan en el título de diversas antologías. Aunque impreciso, el término tendría la ventaja de remitir a un arco de significados que se contrapone, o ha sido percibida en conflicto, con la denominada, también difusamente, poesía pura, aquella que privilegiaría el lenguaje, las metáforas, la experimentación, la forma. Sería el arte por el arte, sin mensaje aparente, pero que instala la duda: ino se podría asegurar que esta también tiene un sentido, además de estético, político y social?

La poesía política en Chile es de larga trayectoria, remonta al siglo XIX, pero fue en el XX que alcanzó su mayor desarrollo, instigada por eventos externos como la Guerra Civil española y la Revolución cubana, o internos, como el Chile socialista (1970-73) o el Golpe de Estado que le siguió. Fueron acontecimientos que tenían como horizonte una revolución. La coyuntura actual, empero, asiste a la propagación de una onda liberal que parece imponerse a contrapelo de las demandas de justicia social y de construcción de sociedades plurales. Rebrotaría aquí, como corolario, un tema ampliamente discutido en las décadas del 60 y 70 , relativo al compromiso social del intelectual y sus dilemas. ¿Un poeta debe reflexionar, en su poesía, sobre estos problemas? ¿Debe ayudar a construir, con su trabajo literario, nuevos horizontes, a forjar nuevas utopías? Me inclino a afirmar que sí, y me encantaría que Dulce patria pudiera representar una contribución en esa dirección. 